\title{
The Benefits of New ARV Prophylaxis in Infants Who are on Exclusive Breast Feeding in Reducing the Risk of Mother to Child Transmission
}

\author{
Hamsa M', Sampath Kumar C ${ }^{2}$, Rajendra V Naidü, Prakash K Wari ${ }^{3}$ \\ ${ }^{1}$ SNCU Specialist, Department of Pediatrics, Chaluvamba Hospital, MMC\&RI, Mysore, 2unior Resident, Department of Pediatrics, Manipal Hospital, Old Airport Road, \\ Bangalore, ${ }^{3}$ Professor, Department of Pediatrics, Karnataka Institute of Medical Sciences, Hubli.
}

\section{Abstract}

Background: Antiretroviral prophylaxis given soon after birth to all HIV exposed infants is effective in reducing MTCT which forms the basis of post exposure prophylaxis strategy. Infant ARV prophylaxis is also highly effective in reducing transmission through breast milk. Subjects and Methods: All mothers were counseled regarding advantages and disadvantages of both exclusive breast feeding and mixed feeding and was started on EBF on their choice. Babies were followed up at birth, 4weeks, 6weeks, 10weeks, 14weeks and monthly thereafter until 6 months of age and during every visit detailed history and clinical examination was performed and entered in preformed proforma. HIV status was evaluated at 6weeks and 6 months of life by direct blood spot for HIV -1 DNA PCR by ICTC and if it was positive it was confirmed by whole blood sample for HIV -1 DNA PCR at ART Centre. Results: At the end of 6 months, most common clinical morbidity noticed in HIV exposed exclusively breast fed infants was clinical pallor in 4(19.0\%), followed by URTI, splenomegaly in 2(9.5\%), and hepatomegaly, loose stools, oral thrush, severe acute malnutrition, and microcephaly was observed in 1(4.8\%) babies. Conclusion: The breast milk of HIV-infected women may confer protection against common infant pathogens.

Keywords: ARV prophylaxis, Infants, Exclusive breast feeding.

Corresponding Author: Dr. Sampath Kumar C, Junior Resident, Depratment of Pediatrics, Manipal Hospital, Old Airport Road,Bangalore.

Received: April 2019

Accepted: April 2019

\section{Introduction}

HIV (Human immunodeficiency virus) / AIDS (Acquired immune deficiency syndrome) is a part of one of the greatest health crisis ever faced by humanity. Pediatric HIV is a growing health challenge worldwide. In 2010, it is estimated that 2.39 million people are living with HIV/AIDS (PLHIV). Out of these, women constitute $39 \%$ while $4.4 \%$ are children. India has low HIV prevalence of $0.34 \%$, yet in terms of individuals infected, India is home to the third largest number of people living with HIV in the world. Nearly 5\% has been attributed to parent to child transmission. Pediatric HIV disease can progress very rapidly to develop clinical AIDS and leads to death in most of the cases within first year of life and often require treatment before a positive diagnosis can be confirmed. ${ }^{[1]}$ There are antiretroviral interventions available to reduce mother to child transmission (MTCT) to HIV low levels, even in context with breast feeding and most extensive of these interventions may achieve MTCT rates as low as $1 \% .^{[2]}$

Without any intervention, the risk of transmission from HIV infected pregnant women to their children is estimated to be around $20-45 \%$. Use of antiretroviral (ARV) drugs has been shown to be quite effective in preventing this transmission.
Extended ARV prophylaxis to mothers and/or infants during breast feeding period will significantly prevent transmission. Postnatal transmission through breast feeding has been demonstrated in number of studies and can vary from 14$44 \% .{ }^{[3]}$ Both free and cell associated virus has been detected in breast milk from HIV infected mothers. A Meta analysis of five different studies of postnatal transmission reported an excess transmission risk by breast feeding of $14 \%$ for women with established HIV infection, and an excess risk of $29 \%$ among women who developed primary infection during the postpartum period. ${ }^{[4]}$ Feeding in the presence of cracked nipples or mastitis, mixed feeding, continuation of breastfeeds for prolonged periods of time, seroconversion of the mother during the postnatal period, high viral load and low CD4 cell counts, all increase the risk of transmission of HIV. Many studies have emphasized the superiority of exclusive breast feeding or formula feeding over mixed feeding. The risk of transmission increases with the duration of breast feeding, although in a nonlinear fashion. ${ }^{[5]}$

Antiretroviral prophylaxis given soon after birth to all HIV exposed infants is effective in reducing MTCT which forms the basis of post exposure prophylaxis strategy. Infant ARV prophylaxis is also highly effective in reducing transmission through breast milk. ${ }^{[6]}$ 


\section{Subjects and Methods}

\section{Methodology:}

All babies who were exposed to HIV positive mother irrespective of mode of delivery and received NVP birth dose within 6 to 12 hours of delivery and prophylaxis continued till 6 weeks according to PPTCT guidelines 2012 by National AIDS Control organization(NACO).

\section{Methods of collection of data:}

- All cases which satisfied the inclusion criteria were taken into the study.

- Purpose of the study was explained to the parents of the study subjects and informed consent was taken

- At the entry point into the study, a base line evaluation in terms of birth weight, length, head circumference and systemic examination was done.

- The following anthropometric measurements were measured as explained below.

I. Birth weight: all neonates were weighed nude on an electronic weighing scale at birth or within half an hour.

II. Length: crown heel length was recorded to the nearest of $0.5 \mathrm{~cm}$ on a infantometer with the baby being supine, knee fully extended and sole of feet held Firmly against the foot board and head touching the fixed board.

1. Head circumference (HC) was recorded using a standard non stretchable tape as per standard guidelines.

- All these were documented in preformed proforma.

- The neonate were given birth dose of nevirapine and was advised to continue till 6 weeks.

- All mothers were counseled regarding advantages and disadvantages of both exclusive breast feeding and mixed feeding and was started on EBF on their choice.

- Babies were followed up at birth, 4weeks, 6weeks, 10 weeks, 14 weeks and monthly thereafter until 6 months of age and during every visit detailed history and clinical examination was performed and entered in preformed proforma.

- HIV status was evaluated at 6 weeks and 6 months of life by direct blood spot for HIV -1 DNA PCR by ICTC and if it was positive it was confirmed by whole blood sample for HIV -1 DNA PCR at ART centre .

- Clinical profile and HIV status of the HIV exposed infants from birth to 6 months of life and benefits of NVP prophylaxis in infants who are on exclusive breast feeding in reducing the risk of mother to child transmission was assessed.

\section{Statistical Analysis}

Statistical analysis was done using SPSS 20 Software.
Statistical methods used were percentages and means.

\section{Results}

Table 1: Mean anthropometry at birth

\begin{tabular}{|l|c|}
\hline Anthropometry parameter & Mean \pm SD \\
\hline Birth weight & $2.787 \pm 0.432 \mathrm{~kg}$ \\
\hline Length at birth & $47.61 \pm 3.13 \mathrm{~cm}$ \\
\hline Head circumference at birth & $32.97 \pm 0.99 \mathrm{~cm}$ \\
\hline
\end{tabular}

In this study, the mean birth weight was $2.787 \pm 0.432 \mathrm{~kg}$. Low birth weight $(<2.5 \mathrm{~kg})$ was noticed in $3(14.2 \%)$ babies. Mean length of babies at birth was $47.61 \pm 3.13 \mathrm{~cm}$. Mean head circumference at birth was $32.97 \pm 0.99 \mathrm{~cm}$.

Table 2: Weight for age at 6 months

\begin{tabular}{|l|l|l|}
\hline Standard deviation & Frequency $(\mathbf{n}=\mathbf{2 1})$ & Percent $\mathbf{( \% )}$ \\
\hline$<-3$ SD & 5 & 23.8 \\
\hline-3 SD to -2SD & 1 & 9.5 \\
\hline$>-2$ SD & 15 & 71.4 \\
\hline Total & 21 & 100.0 \\
\hline
\end{tabular}

The parameter of weight for age at 6 months showed <-3SD in $5(23.8 \%)$ i.e. severe wasting, between -3SD to -2SD in $1(4.8 \%)$ i.e. wasting, and $>-2$ SD in $15(71.4 \%)$ babies i.e. normal.

Table 3: Length for age at 6months

\begin{tabular}{|l|l|l|}
\hline Standard deviation & Frequency $(\mathbf{n = 2 1})$ & Percent $(\boldsymbol{\%})$ \\
\hline$<-3 S D$ & 4 & 19.0 \\
\hline -3SD to -2SD & 4 & 19.0 \\
\hline$>-2$ SD & 13 & 61.9 \\
\hline Total & 21 & 100.0 \\
\hline
\end{tabular}

The length for age at 6 months among 21 babies included in the study, were <-3SD in 4 (19\%) i.e. severe stunting, between -3SD to -2SD in 4(19\%) i.e. stunting, and >-2SD in $13(61.9 \%)$ babies.

Table 4: Weight for length at 6 months

\begin{tabular}{|l|l|l|}
\hline Standard deviation & Frequency $(\mathbf{n}=\mathbf{2 1})$ & Percent $\mathbf{( \% )}$ \\
\hline$<-3 S D$ & 1 & 4.8 \\
\hline -3SD to -2SD & 2 & 9.5 \\
\hline$>-2$ SD & 18 & 85.7 \\
\hline Total & 21 & 100.0 \\
\hline
\end{tabular}

The weight for length at 6 month of age were <-3SD in 1 $(4.8 \%)$ i.e. severe acute malnutrition, between $-3 \mathrm{SD}$ to $-2 \mathrm{SD}$ in $2(9.5 \%)$ i.e. moderate acute malnutrition, and normal in the rest of the babies i.e. $>-2$ SD in $18(85.7 \%)$.

Table 5: Nutritional status at 6 months of age in HIV exposed babies

\begin{tabular}{|l|l|l|}
\hline Nutritional status & No of cases $(\mathbf{n}=\mathbf{2 1})$ & Percentage $(\%)$ \\
\hline Wasting & 8 & 38.0 \\
\hline Stunting & 3 & 14.2 \\
\hline
\end{tabular}

The nutritional status of the 21 babies at 6 months of age April-June 2019 
who received EBF and NVP prophylaxis showed wasting in $8(38.0 \%)$ and stunting in $3(14.2 \%)$.

\section{Table 6: Head circumference at 6 months of age}

\begin{tabular}{|l|l|l|}
\hline $\begin{array}{l}\text { Standard } \\
\text { deviation(SD) }\end{array}$ & Frequency $(\mathbf{n = 2 1})$ & Percentage $(\boldsymbol{\%})$ \\
\hline$<-3$ SD & 1 & 4.8 \\
\hline$>-3$ SD & 20 & 95.2 \\
\hline Total & 21 & 100 \\
\hline
\end{tabular}

Head circumference among these 21 babies at 6 months of age showed microcephaly with head circumference <-3SD only in $1(4.8 \%)$ and remaining 20 (95.2\%) babies had normal head circumference.

\begin{tabular}{|c|c|c|c|}
\hline Morbidity & $\begin{array}{l}\text { Episodes (up } \\
\text { to } 6 \text { weeks) } \\
(\%), n=30\end{array}$ & $\begin{array}{l}\text { Episode } \quad(6 \\
\text { wks to } 3 \\
\text { months) } \\
(\%), n=30\end{array}$ & $\begin{array}{l}\text { Episode }(3 \\
\text { months to } 6 \\
\text { months) } \\
(\%), n=30\end{array}$ \\
\hline clinical pallor & 0 & $2(9.5)$ & $11(52.38)$ \\
\hline URTI & 0 & 0 & $2(9.5)$ \\
\hline LRTI & $1(4.8)$ & 0 & 0 \\
\hline Fever & 0 & $1(4.8)$ & $2(9.5)$ \\
\hline Hepatomegaly & 0 & 0 & $1(4.8)$ \\
\hline Splenomegaly & 0 & 0 & $2(9.5)$ \\
\hline Lymphadenopathy & 0 & 0 & 0 \\
\hline Oral thrush & 0 & $1(4.8)$ & 0 \\
\hline Diarrhea & 0 & $1(4.8)$ & 0 \\
\hline Otitis media & 0 & 0 & 0 \\
\hline Jaundice & 0 & 0 & 0 \\
\hline Ascites & 0 & 0 & 0 \\
\hline Skin lesions & 0 & 0 & 0 \\
\hline
\end{tabular}

Table 8: Clinical profile of exclusively breast fed HIV exposed babies at 6 months of age $(n=21)$

\begin{tabular}{|c|l|c|c|}
\hline S.no & Signs & No of cases & Percent \\
\hline 1 & Severe acute malnutrition & 1 & $4.8 \%$ \\
\hline 2 & Pallor & 4 & $19.0 \%$ \\
\hline 3 & URTI & 2 & $9.5 \%$ \\
\hline 4 & Hepatomegaly & 1 & $4.8 \%$ \\
\hline 5 & Splenomegaly & 1 & $9.5 \%$ \\
\hline 6 & Diarrhoea & 1 & $4.8 \%$ \\
\hline 7 & Oral thrush & 1 & $4.8 \%$ \\
\hline 8 & Microcephaly & 0 & $4.8 \%$ \\
\hline 9 & Developmental delay & 0 & 0 \\
\hline 10 & Lymphadenopathy & 0 & 0 \\
\hline 11 & Hepatosplenomegaly & 0 & 0 \\
\hline 12 & LRTI & 0 & 0 \\
\hline 13 & Signs of vitamin deficieny & 0 & 0 \\
\hline 14 & CSOM & 0 & 0 \\
\hline 15 & Skin manifestations & 0 & 0 \\
\hline 16 & Parotitis & 0 & 0 \\
\hline 17 & CNS manifestations & 0 & 0 \\
\hline 18 & Ascites & & \\
\hline
\end{tabular}

At the end of 6 months, most common clinical morbidity noticed in HIV exposed exclusively breast fed infants was clinical pallor in 4(19.0\%), followed by URTI, splenomegaly in 2(9.5\%), and hepatomegaly, loose stools, oral thrush, severe acute malnutrition, and microcephaly was observed in $1(4.8 \%)$ babies.

Among 21 babies included in the study, all 21 babies had received Nevirapine at birth and prophylaxis for 6 weeks and all 21 babies were started on cotrimoxazole prophylaxis at 6 weeks and continued thereafter.

"The HIV status was evaluated by DNA PCR at the end of 6 weeks and 6 months and was found to be negative in all the 21 babies".

\section{Discussion}

All the 21 mothers enrolled in the study had received some form of PMTCT measure before, during and after delivery and none of the mothers were devoid of any form of therapy or prophylaxis.

In the Mumbai study quoted by NACO, showed an apparent decrease in transmission rates by more than $50 \%$ in women who received PMTCT measures. The results found in this study showed that there is $100 \%$ apparent reduction in risk of vertical transmission noticed in whom the mothers had received appropriate PMTCT measures along with EBF for babies up to 6 months of age and NVP prophylaxis for 6 weeks duration.

So in the present scenario all mothers who are seropositive should receive PMTCT measures despite their affordability and place of origin. This would lead to a considerable decrease in mother to child transmission, which accounts for more than $90 \%$ of the route of transmission in children as told earlier.

There were a total of 15 spontaneous vaginal deliveries and 5 LSCS in our study, many other confounding factors were not eliminated (obstetric factors, fetal factors etc.). However our study did not show any relation between mode of delivery and risk of vertical transmission. This is contradictory to the present data, which has shown a beneficial effect of Elective LSCS over vaginal delivery.

A RCT conducted by European mode of delivery collaboration has shown a vertical transmission rate of $2.4 \%$ in elective LSCS compared to emergency LSCS where transmission rate was found to be $8.4 \%$. In another prospective study by Esquilin et al, they have demonstrated the odds ratio of 0.8 for cesarean vs vaginal delivery.7 In fact Cesarean section before labor and before ruptured membranes ("elective cesarean section", or ECS) has been introduced as an intervention for the prevention of motherto-child transmission (MTCT) of HIV-1. Further studies are required with elective LSCS to compare the benefits of elective LSCS over vaginal deliveries.

In our study all 30 babies received NVP birth dose within 12 hours of birth and was continued with NVP prophylaxis up to 6 weeks of age as per NACO which showed potential to reduce the risk of mother to child transmission to less than $5 \%$ in breastfeeding populations and less than $2 \%$ in non-breast feeding populations, but our study showed zero 
percent mother to child transmission risk when NVP prophylaxis was combined with exclusive breast feeding and with appropriate $\mathrm{ARV}$ prophylaxis to mother.

The latest national nutritional status data for Indian infants 0-6 months in the general population showed $23 \%$ stunting, $32 \%$ underweight, and $31 \%$ wasting. The nutritional status of infants in the same age group in some of the African countries is comparatively better than those in India, with 9\%-19\% stunted, and 3\%-16\% wasted. Hence, the baseline levels of malnutrition among Indian infants in the community are far worse to begin with than in many other resource-constrained regions.

In a study by Ram $\mathrm{M}$ et $\mathrm{al},{ }^{[8]}$ there was an overall high prevalence of malnutrition with HIV-exposed infants having approximately $47 \%$ stunting and $10 \%$ wasting. In a retrospective study of 162 HIV exposed infants at a Regional Pediatric Center for HIV in Delhi, prevalence of wasting and stunting was $50.5 \%$ and $48.8 \%$, respectively. While in our study the prevalence of

Wasting $8(38.0 \%)$ and stunting $3(14.2 \%)$ in HIV exposed exclusively breast fed infants was less when compared to the above studies.

In our study, out of 21 babies, most common morbidity noticed within 6 weeks of age was LRTI 1 (4.8\%) which was not the same when compared with a study conducted by Trivedi et al9which showed most common clinical morbidity as diarrhea $12(28.57 \%)$ followed by fever $5(11.90 \%)$, URTI (4.76\%), LRTI $(4.76 \%)$, lymphadenopathy $2(4.76 \%)$,oral thrush $(4.76 \%)$, otitis media and skin lesions $1(2.38 \%)$ each.

Most common clinical morbitiy noted between 6 weeks to 3 months of age in our study was severe pallor $2(9.5 \%)$,followed by fever, oral thrush and diarrhea $1(4.8 \%)$ each which was not the same as study by Trivedi et al. ${ }^{[9]}$

Most common clinical morbidity noticed between 3 months to 6 months of age in our study was clinical pallor $10(47.6 \%)$ babies, followed by splenomegaly $2(9.5 \%)$, URTI 2(9.5\%), fever 2(6.66\%), and hepatomegaly $1(4.8 \%)$ which was different when compared with Trivedi et al study. ${ }^{[9]}$

Overall the episodes and percentage of morbidity noticed in our study group, exclusively breast fed HIV exposed babies on NVP prophylaxis was very less when compared to study of Trivedi et al, this finding might probably be due to first, exclusive breast feeding given to the infants which has protective effects from common childhood morbidities and secondly may be due to timely appropriate initiation and continuation of chemoprophylaxis in both mother and baby which has played role in decreasing vertical transmission and further morbidities due to disease itself but this has to be confirmed by further studies with large sample size focusing towards it. ${ }^{[10]}$

\section{Conclusion}

In our study, we noticed 100 percent reduction in vertical transmission in HIV exposed babies who were given exclusive breast feeding till 6 months and NVP prophylaxis for 6 weeks. And the morbidities recorded in HIV exposed exclusively breastfed infants was very mild with no mortality at 6 months follow up period which could be partly attributed to breast feeding. Thus, the breast milk of HIV-infected women may confer protection against common infant pathogens. Along with that Extended ARV prophylaxis to mothers and/or infants during the breastfeeding period helps significantly in preventing transmission of the disease.

\section{References}

1. Government of Karnataka, Department of Health and Family Welfare. Prevention of Parent-To-Child Transmission New Guidelines 2012 (Bangalore):Karnataka State AIDS Prevention Society;2012.

2. Shapiro RL, Lockman S. Mortality among HIV-exposed infants: the first and final frontier. Clinical infectious diseases : an official publication of the Infectious Diseases Society of America. 2010;50(3):445-447.

3. Adhikari M, Kauchali S, Moodley A. Clinical profile and morbidity pattern of infants born to HIV infected mothers in Durban South Africa. Indian pediatrics. 2006;43(9):804-808.

4. Kourtis AP, Jamieson DJ, de Vincenzi I, Taylor A, Thigpen MC, Dao $\mathrm{H}$, et al. Prevention of human immunodeficiency virus-1 transmission to the infant through breastfeeding: new developments. American journal of obstetrics and gynecology. 2007;197(3 Suppl):S113-122.

5. Seth A, Chandra J, Gupta R, Kumar P, Aggarwal V, Dutta A. Outcome of HIV exposed infants: experience of a regional pediatric center for HIV in North India. Indian journal of pediatrics. 2012;79(2):188-193.

6. Kumwenda NI, Hoover DR, Mofenson LM, Thigpen MC, Kafulafula $\mathrm{G}, \mathrm{Li} \mathrm{Q}$, et al. Extended antiretroviral prophylaxis to reduce breast-milk HIV-1 transmission. The New England journal of medicine. 2008;359(2):119-129.

7. Esquilin IO, Hutto C. Mechanism of HIV transmission and clinical presentation. Immun Allerg Clin North Am 1995; 15(2): 205-223.

8. Ram M, Gupte N, Nayak U, Kinikar A A, Khandave M, Shankar A V et al. Growth patterns among HIV-exposed infants receiving nevirapine prophylaxis in Pune, India. BMC Infectious Diseases 2012, $12: 282$

9. Trivedi S, Kariya P, Shah V, Mody S, Patel P, Desai K. Does maternal HIV status affect infant Growth?: a hospital based follow up study. National journal of medical research 2012; 2(4):512-517.

10. Ryder RW, Nsa W, Hassing SE, et al: Perinatal transmission of human immune deficiency virus type 1 to infants of seropositive women in Zaire. N Engl J Med1989; 320: 1637-1642. 
Copyright: () the author(s), 2019. It is an open-access article distributed under the terms of the Creative Commons Attribution License (CC BY 4.0), which permits authors to retain ownership of the copyright for their content, and allow anyone to download, reuse, reprint, modify, distribute and/or copy the content as long as the original authors and source are cited.

How to cite this article: Hamsa M, Kumar CS, Naidu RV, Wari PK. The Benefits of New ARV Prophylaxis in Infants Who are on Exclusive Breast Feeding in Reducing the Risk of Mother to Child Transmission. Asian J. Clin. Pediatr. Neonatol.2019;7(2):22-26.

DOI: dx.doi.org/10.21276/ajcpn.2019.7.2.6

Source of Support: Nil, Conflict of Interest: None declared. 